\title{
Pectobacterium and Dickeya Responsible for Potato Blackleg Disease in New York State in 2016
}

Xing Ma and Allison Schloop, Plant Pathology and Plant-Microbe Biology Section, School of Integrative Plant Science, Cornell University, Ithaca, NY 14853; Bryan Swingle, Emerging Pests and Pathogens Research Unit, Robert W. Holley Center, United States Department of Agriculture-Agricultural Research Service, Ithaca, NY 14853; and Plant Pathology and Plant-Microbe Biology Section, School of Integrative Plant Science, Cornell University, Ithaca, NY 14853; and Keith L. Perry, ${ }^{\dagger}$ Plant Pathology and Plant-Microbe Biology Section, School of Integrative Plant Science, Cornell University, Ithaca, NY 14853

\begin{abstract}
Beginning in 2014, outbreaks of blackleg disease compromised potato (Solanum tuberosum) production in the northeastern United States. Disease severity was atypical for plantings with certified seed. During 2016, 43 samples with blackleg symptoms were analyzed, originating from more than 20 farms operating in New York State. A combination of techniques was employed to identify the blackleg pathogens: isolation in vitro, diagnostic PCR assays for Pectobacterium and Dickeya sp., pathogenicity assays, and DNA sequencing. Twenty-three bacterial isolates were obtained, the majority of which were designated $D$. dianthicola or $P$. parmentieri;

two of the isolates were designated $P$. atrosepticum. All isolates were pathogenic in stem lesion and tuber soft rot assays and exhibited pectin degrading activity (pitting) in crystal violet pectate agar medium. Phylogenetic analyses of $d n a X$ gene sequences placed all but one of the isolates into clades corresponding to $D$. dianthicola, $P$. parmentieri, or $P$. atrosepticum. One atypical isolate clustered with $P$. carotovorum subspecies. Data are consistent with the hypothesis that $D$. dianthicola from New York and the northeast are part of a single clade, and at least three different soft rot bacteria were associated with blackleg during 2016 in New York.
\end{abstract}

During 2014 and in subsequent years, outbreaks of blackleg disease in potato have been observed in New York and other areas of the northeastern United States (Hao et al. 2016; Jiang et al. 2016; Johnson 2016). In severely affected fields, plants failed to emerge, resulting in uneven stands and in some cases, complete crop loss (McGrath 2017). Some emerging plants exhibited rotting stems and plant death. A combination of the severity of the disease and the sudden appearance across multiple eastern states was unusual and presents a threat to commercial and seed potato production. The increase of this disease is not limited to the eastern United States, as there have been reports of an increase of blackleg in the central and western potato production areas during the same recent timeframe (Dung et al. 2012; McNally et al. 2017a, b, 2018).

Blackleg is a seedborne bacterial disease that occurs worldwide wherever potatoes are grown. The bacterial pathogen typically originates from the seed potato and moves upward in emerging sprouts (Pérombelon 1974, 2002). Symptoms are environmentally conditioned and can range from asymptomatic to small water-soaked lesions at the base of stems to an extensive wet rot or a drier rot of the pith, and the death of the shoot. A related disease is aerial stem rot, sometimes referred to as aerial blackleg. These are soft rot diseases that affect the

${ }^{\dagger}$ Corresponding author: K. L. Perry; E-mail: KLP3@cornell.edu

Funding: This work was funded in part by the USDA-ARS State Partnership Potato Funding program, the United States Department of Agriculture, National Institute of Food and Agriculture, and the Empire State Potato Growers.

Accession numbers for dnaX genes (isolate - accession number): ME23 - MF954601; NY1528B - MF954602; NY1532B - MF954603; NY1533B - MF954604; NY1548A - MF954605; NY1589H - MF954606; NY1563A - MF954607

Mention of trade names or commercial products in this publication is solely for the purpose of providing specific information and does not imply recommendation or endorsement by the U.S. Department of Agriculture. USDA is an equal opportunity provider and employer.

Accepted for publication 14 March 2018.

This article is in the public domain and not copyrightable. It may be freely reprinted with customary crediting of the source. The American Phytopathological Society, 2018. stems of growing plants and differ from tuber soft rot that affects tubers in the ground and in storage. An understanding of these diseases is made difficult by the fact that there are an increasing number of pathogens being recognized as associated with soft rot diseases.

The primary pathogens associated with soft rot of potato and other crop plants are gram negative, facultatively anaerobic members of the family Enterobacteriaceae, with the common property of being able to degrade pectin facilitating the rotting (Pérombelon and Kelman 1980). The bacteria are primarily members of the genera Pectobacterium and Dickeya (formerly Erwinia) (Czajkowski et al. 2015; Humphris et al. 2015). P. atrosepticum is the classic potato blackleg pathogen, and differs from other soft rot pathogens in its relatively narrow host range, being limited to the plant family Solanaceae (Gardan et al. 2003; Glasner et al. 2008). In contrast, a number of subspecies of $P$. carotovorum and species of Dickeya cause soft rot disease in potato and many other hosts. Related pathogens have been discovered associated with potato disease problems in different parts of the world, in particular D. dianthicola and D. solani (Bobev et al. 2014; Toth et al. 2011; van der Wolf et al. 2014). Numerous distinct pathogens have been described as subspecies of $P$. carotovorum, notably $P$. carotovorum subsp. carotovorum, $P$. carotovorum subsp. brasiliense (Zhang et al. 2016), and $P$. carotovorum subsp. wasabiae (with potato isolates of the latter now designated as $P$. parmentieri) (Khayi et al. 2016). This evolving nomenclature is a consequence of more detailed studies of the pathogens, dynamic populations, and the emergence of new pathogens.

The most definitive means of identifying soft rot pathogens is to isolate the disease-associated bacteria and confirm pathogenicity prior to performing biochemical and/or nucleic acid sequence analyses. PCR testing of diseased tissue followed by DNA sequencing is proving to be a reliable alternative, and a number of primer sets are currently employed. The primer pairs Df/Dr and ADE1/ADE2 target the 16S-23S intergenic spacer and pectate lyase genes of Dickeya spp., respectively (Laurila et al. 2010; Nassar et al. 1996), and the Y45/Y46 (Frechon et al. 1998) and ExpccF/ExpccR (Kang et al. 2003) pairs detect Pectobacterium species, with the Y45/Y46 pair being specific for $P$. atrosepticum (Humphris et al. 2015; Potrykus et al. 2014). A follow up of sequencing these or other amplified products in combination with phylogenetic analyses provides a confirmation of the pathogen's taxonomic affiliation.

Paralleling the complexity of the nomenclature is an understanding of the biological properties of these different bacteria and the 
epidemiology associated with any specific pathogen or isolate. Blackleg is a seedborne disease and has traditionally been managed through a combination of seed certification, to eliminate severely affected seed lots, and sanitation practices to curtail spread to uninfected plants and tubers (Pérombelon 1974, 2002). Although the pathogens are not thought to survive well in soil, especially in cold climates with severe winters, a number of the Pectobacterium spp. and Dickeya spp. have wide host ranges and can survive on alternate hosts (Pérombelon and Kelman 1980). Confounding management of blackleg is an ability of some or all of the pathogens to persist asymptomatically in an infected plant when conditions are not conducive to disease (Pérombelon 2002). In order to effectively manage new blackleg pathogens or strains as they emerge, it is essential to understand their biological properties and how they persist in the environment in order to disrupt transmission from crop to crop.

A first step toward understanding and managing the recent blackleg disease outbreak in the northeastern United States is to determine the identity of the pathogen(s) associated with the disease. An initial assessment of the disease in Maine by Jiang et al. uncovered $D$. dianthicola as the primary pathogen (Jiang et al. 2016), although these same workers recently reported $P$. parmentieri as associated with blackleg (Ge et al. 2018). The objective of this study was to isolate bacteria associated with blackleg disease in New York State in 2016, to confirm the pathogenicity of isolates, and to determine their identity through a phylogenetic assessment of dnaX sequences.

\section{Materials and Methods}

Plant sampling, processing, and bacterial isolations. Samples of field-grown potato plants with wilting, basal stem necrosis, hollow stem, and/or vascular streaking (discoloration) were collected during July and August 2016 from commercial potato production farms in several New York State potato growing regions (Fig. 1). Samples were bagged, transported to Cornell University overnight, stored at $4^{\circ} \mathrm{C}$, and processed within 24 to $48 \mathrm{~h}$. Pieces of stem tissue from the edges of advancing necrosis (approximately $0.2 \mathrm{~g}$ ) were removed for bacterial isolation. Seventeen of the 43 samples received in 2016 were also processed for total plant and microbial DNA extraction and PCR analysis (described below).

For bacterial isolation, stem tissue was surface-sterilized in $70 \%$ ethanol for $10 \mathrm{~s}$ and subsequently minced and soaked in $1 \mathrm{ml}$ sterile water for $30 \mathrm{~min}$. Alternatively, samples were dipped in a $30 \%$ solution of commercial bleach (1.5\% final concentration sodium hypochlorite) for $10 \mathrm{~s}$, wiped dry, and then soaked in water. The resulting solutions were spread on either crystal violet pectate (CVP) agar medium made with DIPECTA, AG366 pectin (Agdia, Elkhart, IN; Hélias et al. 2012), or LB agar medium (Sambrook et al. 1989). Agar plates were incubated at $28^{\circ} \mathrm{C}$ for 24 to $48 \mathrm{~h}$. Colonies were selected based on uniformity of type and/or for pit formation on CVP medium, restreaked on LB plates to isolate single colonies, and stored in LB with $16 \%$ glycerol at $-80^{\circ} \mathrm{C}$.

Nucleic acid extraction and PCR. Total plant and microbial DNA was prepared from plant tissue using the FastDNA SPIN Kit for Soil (MP Biochemicals, Santa Ana, CA). Bacterial genomic DNA was prepared from cells grown in LB broth using the Wizard DNA Purification Kit (Promega, Madison, WI). The resulting DNA samples were adjusted to $50 \mathrm{ng} / \mu \mathrm{l}$ for PCR. PCR reactions with primer sets: Df/Dr and ADE1/ADE2 (Humphris et al. 2015; Potrykus et al. 2016) were performed as previously described to detect Dickeya spp. Multiplex PCR assays with PCR primers Y45/Y46 and ExpccF/ExpccR were performed to detect Pectobacterium species (Humphris et al. 2015; Potrykus et al. 2016). Reference isolates of Dickeya and Pectobacterium species were from the collection at Cornell University or those obtained from Amy Charkowski (Colorado State University); these are identified in Table 1 as 'reference.'

Pathogenicity tests. The Solanum tuberosum cultivar Reba was used in tuber and stem assays. For tuber assays, $5 \mu \mathrm{l}$ of a bacterial suspension grown overnight at $28^{\circ} \mathrm{C}$ in LB broth or a smear on a toothpick of bacteria grown overnight at $28^{\circ} \mathrm{C}$ on $\mathrm{LB}$ agar was deposited into an approximately $5 \mathrm{~mm}$ deep wound made in a tuber using a flat (or round) wooden toothpick or a $2.2 \mathrm{~mm}$ wide wooden applicator stick (Puritan Medical Products, Guilford, ME). Negative controls ( $5 \mu$ l sterile LB broth or no addition to the wound site) and positive controls were included on each potato tuber along with the experimental bacterium, all performed in duplicate on the same tuber (i.e., with two puncture sites for each treatment). The positive controls were $D$. dianthicola ME23 and $P$. carotovorum subsp. carotovorum WPP14 (provided by Amy Charkowski, University of Colorado). Inoculated tubers were incubated at $29^{\circ} \mathrm{C}$ for $24 \mathrm{~h}$ and then examined visually for tissue decay, i.e., softening (maceration) and discoloration. Samples with tissue decay symptoms distinct from the negative control were rated as positive (pathogenic). The stem assays were conducted using potato plants $(20$ to $46 \mathrm{~cm}$ [8 to 18 inches] tall) grown in a greenhouse from sprouted tubers or shoot cuttings rooted 2 to 4 weeks prior. One wound per stem was made in the basal stem region above the soil line using wooden toothpicks as described above for tuber assays, except stem wounds were sealed with vacuum grease to prevent drying. In each experiment, three stems were inoculated per treatment. Symptom development was rated at 3 and 7 days postinoculation. Isolates causing rotting and/or internal brown discoloration spreading from the wound site were rated as positive (pathogenic). Each bioassay was performed at least twice.

dnaX sequence typing. A 535-bp segment of the $d n a X$ gene was PCR amplified from bacterial DNA samples using dnaXf/dnaXr primers as described in Sławiak et al. (2009). Amplification of the correct size product was confirmed by agarose gel electrophoresis prior to sequencing the PCR product. To prepare sequencing reactions, $5 \mu \mathrm{l}$ aliquots of PCR products were treated with $2 \mu \mathrm{l}$ ExoSAP-IT (Affymetrix, Cleveland, $\mathrm{OH}$ ) and sequenced using dnaXf and dnaXr primers. Forward and reverse sequence reads from sequencing results were aligned with Vector NTI Suite 8.0 (Thermo Fisher Scientific) to produce a consensus sequence for each isolate. Consensus sequences were used to search the RefSeq Representative Genome Database (2015/9/ 30) using nucleotide BLAST (Altschul et al. 1990) to identify a set of bacteria with the closest matches to the isolate's dnaX genes. The dnaX consensus sequences and those of the bacteria identified by BLAST were aligned and analyzed using MEGA 7.0 (https:// www.megasoftware.net/). Maximum likelihood trees were constructed to estimate the phylogenetic relatedness. Bacterial reference strains (and sequence accessions) used in the phylogenetic analysis are: D. dianthicola strains IPO 980 (GCA_000430955) and GBBC 2039 (GCA_000365365), P. atrosepticum isolates SCRI 1043 (GCA_000011605) and ATCC33260 (GCA_001038685), $P$. parmentieri isolate WPP163 (GCA_000024645), P. wasabiae

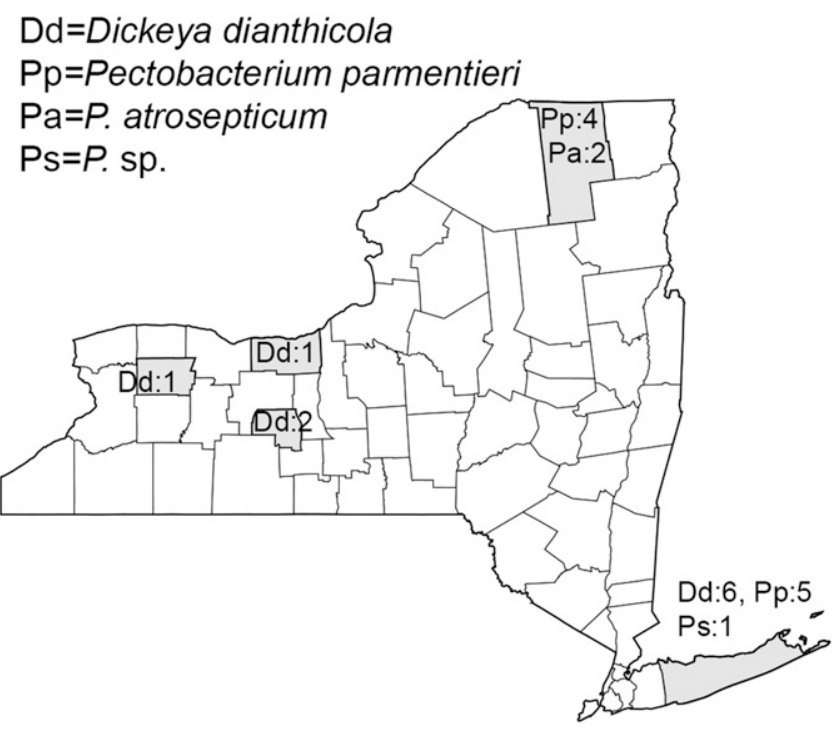

Fig. 1. Map showing the distribution of bacterial isolates collected from potato with blackleg symptoms in New York State. The numbers following the species initials indicate the corresponding number of isolates from that site. 
ATCC43316 (GCA_001742185), P. carotovorum subsp. brasiliensis PBR1692 (GCA_000365365), P. carotovorum subsp. brasiliense strains SX309 (GCA_002068115), P. atrosepticum IPO998 (GQ904832), P. carotovorum subsp. carotovorum PCC21 (GCA_000294535), P. carotovorum subsp. carotovorum WPP14 GCA_000173155), P. carotovorum subsp. carotovorum ATCC 15713 (GCA_001039055), D. chrysanthemi NCPPB 3533 (GCA_000406245), D. zeae NCPPB 3531 (GCA_000406225), D. zeae NCPPB 2538 (GCA_000406165), D. dadantii NCPPB 898 (GCA_000406145), D. dadantii NCPPB 3537 (GCA_000406265), D. dadantii 3937 (GCA_000147055), D. solani IPO 2222 (GCA_001644705), and D. solani IFB 0099 (GCA_000831935).

\section{Results}

Isolation of blackleg pathogens from diseased potato plants. During July and August of 2016, we received a total of 43 samples of young potato plants with blackleg disease symptoms from more than 20 commercial potato production farms operating in five counties of New York State (Fig. 1). These farms are located in three geographically distinct regions of New York (Long Island, the Adirondack Mountains, and the Finger Lakes) all operating independently under separate ownership. We inspected the plants upon arrival and observed wilting, basal stem necrosis, hollow stems, and/or vascular streaking (discoloration) symptoms consistent with blackleg disease associated with soft rot bacteria such as Pectobacterium or Dickeya spp. (Fig. 2).
To isolate and characterize the bacteria responsible for these blackleg symptoms, we cultured endophytic bacteria from plant tissue at the advancing margin of the diseased area. After surface sterilization, plant tissue was minced and soaked in sterile water to allow bacterial cells to migrate or diffuse from the plant tissue. This solution was spread and incubated on LB and CVP agar to culture the bacteria and screen for those with pectinolytic activity characteristic of many soft-rot Enterobacteriaceae (Cuppels and Kelman 1974). Each sample gave rise to multiple colonies that could be grouped based on their morphology; in most cases, one to five colony types grew from each sample. A representative of each colony type was isolated from all of the samples. These isolates were retested to evaluate their pectinolytic phenotypes by observing their ability to cause pitting on CVP medium. Pitting on CVP medium was clearly evident for all of the isolates shown to be pathogenic $(n=23)$, and pitting was not observed for the nonpathogenic isolates (Table 1). All bacterial isolates were tested for their reaction in diagnostic PCR assays and for pathogenicity in bioassays.

PCR testing of bacterial isolates and plant samples. Four sets of primers designed to detect genomic sequences of either Pectobacterium spp. (primer sets Y45/Y46 or ExpccF/R) or Dickeya spp. (primer sets Df/Dr and ADE1/ADE2) were used to test purified genomic DNA from all of the bacterial isolates. A total of 22 isolates were recovered that tested PCR positive as either Pectobacterium or Dickeya spp. Specifically, Dickeya DNA was detected in 10 isolates,

Table 1. Phenotypic properties of blackleg associated phytopathogenic enterobacteria isolated from potato plants in New York State in 2016 with reference species isolates for comparison

\begin{tabular}{|c|c|c|c|c|c|c|c|c|c|}
\hline \multirow[b]{2}{*}{ Species $^{\mathbf{a}}$} & \multirow[b]{2}{*}{ Strain ID } & \multirow[b]{2}{*}{$\begin{array}{l}\text { Pitting on } \\
\text { CVPb }^{\mathbf{b}}\end{array}$} & \multirow[b]{2}{*}{$\begin{array}{l}\text { Tuber } \\
\text { assay }^{c}\end{array}$} & \multirow[b]{2}{*}{$\begin{array}{c}\text { Stem } \\
\text { assayd }\end{array}$} & \multicolumn{4}{|c|}{$\mathbf{P C R}^{\mathrm{e}}$} & \multirow[b]{2}{*}{ County ${ }^{f}$} \\
\hline & & & & & Df/Dr & $\begin{array}{l}\text { ADE1/ } \\
\text { ADE2 }\end{array}$ & $\begin{array}{l}\text { Y45/ } \\
\text { Y46 }\end{array}$ & ExpccF/R & \\
\hline Dickeya dianthicola & ME23 & 1 & 1 & 1 & 1 & 1 & O & 0 & Reference \\
\hline D. dianthicola & $1528 \mathrm{~B}$ & 1 & 1 & 1 & 1 & 1 & 0 & 0 & Suffolk \\
\hline D. dianthicola & 1536B & 1 & 1 & 1 & 1 & 1 & 0 & 0 & Suffolk \\
\hline D. dianthicola & 1538B & 1 & 1 & 1 & 1 & 1 & 0 & 0 & Suffolk \\
\hline D. dianthicola & 1547B & 1 & 1 & 1 & 1 & 1 & 0 & 0 & Suffolk \\
\hline D. dianthicola & $1556 \mathrm{C}$ & 1 & 1 & 1 & 1 & 1 & 0 & 0 & Suffolk \\
\hline D. dianthicola & $1557 \mathrm{~A}$ & 1 & 1 & 1 & 1 & 1 & 0 & 0 & Yates \\
\hline D. dianthicola & $1558 \mathrm{D}$ & 1 & 1 & 1 & 1 & 1 & 0 & 0 & Wayne \\
\hline D. dianthicola & $1559 \mathrm{C}$ & 1 & 1 & 1 & 1 & 1 & 0 & 0 & Yates \\
\hline D. dianthicola & $1562 \mathrm{C}$ & 1 & 1 & 1 & 1 & 1 & 0 & 0 & Suffolk \\
\hline D. dianthicola & $1578 \mathrm{~A}$ & 1 & 1 & 1 & 1 & 1 & 0 & 0 & Genesee \\
\hline Pectobacterium atrosepticum & 1043 & 1 & 1 & 1 & $\mathbf{0}$ & $\mathbf{0}$ & 1 & $\mathbf{0}$ & Reference \\
\hline P. atrosepticum & $1586 \mathrm{~A}$ & 1 & 1 & 1 & 0 & 0 & 1 & 0 & Franklin \\
\hline P. atrosepticum & $1589 \mathrm{H}$ & 1 & 1 & 1 & 0 & 0 & 1 & 0 & Franklin \\
\hline $\begin{array}{l}\text { Pectobacterium carotovorum subsp. } \\
\text { carotovorum }\end{array}$ & WPP14 & 1 & 1 & 1 & $\mathbf{0}$ & $\mathbf{0}$ & $\mathbf{0}$ & 1 & Reference \\
\hline Pectobacterium parmentieri & WPP163 & 1 & 1 & 1 & $\mathbf{0}$ & $\mathbf{0}$ & $\mathbf{0}$ & 1 & Reference \\
\hline P. parmentieri & $1527 \mathrm{~A}$ & 1 & 1 & 1 & 0 & 0 & 0 & 1 & Suffolk \\
\hline P. parmentieri & $1532 \mathrm{~B}$ & 1 & 1 & 1 & 0 & 0 & 0 & 1 & Suffolk \\
\hline P. parmentieri & 1533B & 1 & 1 & 1 & 0 & 0 & 0 & 1 & Suffolk \\
\hline P. parmentieri & $1548 \mathrm{~A}$ & 1 & 1 & 1 & 0 & 0 & 0 & 1 & unknown \\
\hline P. parmentieri & $1584 \mathrm{~A}$ & 1 & 1 & 1 & 0 & 0 & 0 & 1 & Franklin \\
\hline P. parmentieri & $1585 \mathrm{~A}$ & 1 & 1 & 1 & 0 & 0 & 0 & 1 & Franklin \\
\hline P. parmentieri & $1587 \mathrm{~A}$ & 1 & 1 & 1 & 0 & 0 & 0 & 1 & Franklin \\
\hline P. parmentieri & $1588 \mathrm{~A}$ & 1 & 1 & 1 & 0 & 0 & 0 & 1 & Franklin \\
\hline P. parmentieri & $1539 \mathrm{~A}$ & 1 & 1 & 1 & 0 & 0 & 0 & 1 & Suffolk \\
\hline P. parmentieri & $1540 \mathrm{~A}$ & 1 & 1 & 1 & 0 & 0 & 0 & 1 & Suffolk \\
\hline Pectobacterium sp. & $1563 \mathrm{~A}$ & 1 & 1 & 1 & 0 & 0 & 0 & 0 & Suffolk \\
\hline Uncharacterized & $1560 \mathrm{~A}$ & 0 & 0 & 0 & 0 & 0 & 0 & 0 & Suffolk \\
\hline Uncharacterized & $1540 \mathrm{~B}$ & 0 & 0 & 0 & 0 & 0 & 0 & 0 & Suffolk \\
\hline Uncharacterized & $1544 \mathrm{~A}$ & 0 & 0 & 0 & 0 & 0 & 0 & 0 & Suffolk \\
\hline
\end{tabular}

a Species designations for the New York isolates follow their grouping in maximum likelihood phylogenetic trees generated based on their dnaX gene sequences.

The entries in bold are reference isolates employed in this study.

${ }^{b}$ Pitting on crystal violet pectate (CVP) media was evaluated after 7 days. $0=$ no pitting; $1=$ pitting.

${ }^{\mathrm{c}}$ The tuber assay for soft rotting activity evaluated after $24 \mathrm{~h} .1=$ soft rot; $0=$ no soft rot.

${ }^{\mathrm{d}}$ Potato stem assay for pathogenicity; symptoms were observed at 3 and 7 days after inoculation. $1=$ stem rotting was observed; $0=$ no stem rotting.

e PCR assays using the four different primer pairs indicated. $1=$ expected amplicon was obtained; $0=$ no expected amplicon.

${ }^{\mathrm{f}}$ Counties in New York State where samples were collected. 'Reference' refers to well characterized strains used for comparison. 
and Pectobacterium DNA was detected in the remaining 12 isolates (Table 1). Consistent with their design, these diagnostic PCR primers only produced positive reaction products of the expected size for bacteria that were pathogenic and subsequently confirmed as Dickeya or Pectobacterium spp. by phylogenetic analyses of $d n a X$ gene sequences (described below), with one exception. No amplicons were produced from pathogenic isolate NY1563A using any of the above primer sets (Table 1).

During the latter part of the 2016 cropping season, we began directly testing symptomatic plant tissue by PCR in parallel with the isolations. For these tests, bacterial and plant (total) DNA was purified from the margins of the advancing necrosis. Total DNAs from 17 of the 43 potato plant samples were extracted and tested with the four sets of diagnostic primers. Fourteen of the 17 plant samples with blackleg symptoms tested positive as either Pectobacterium or Dickeya spp. One of the 17 samples was PCR positive for both Dickeya and Pectobacterium, but only Dickeya was isolated (NY1556C). Dickeya was also isolated from one of the three PCR negative samples, and purified DNA from this isolate (NY1562C) subsequently tested PCR positive as a Dickeya sp. with primer sets Df/Dr and ADE1/ADE2.

Bioassays for pathogenicity. All bacterial isolates obtained from plant samples were initially screened for their soft rotting activity in a potato tuber bioassay. This assay clearly differentiated pathogenic isolates with soft rotting ability (Table 1, Fig. 3). In all inoculations
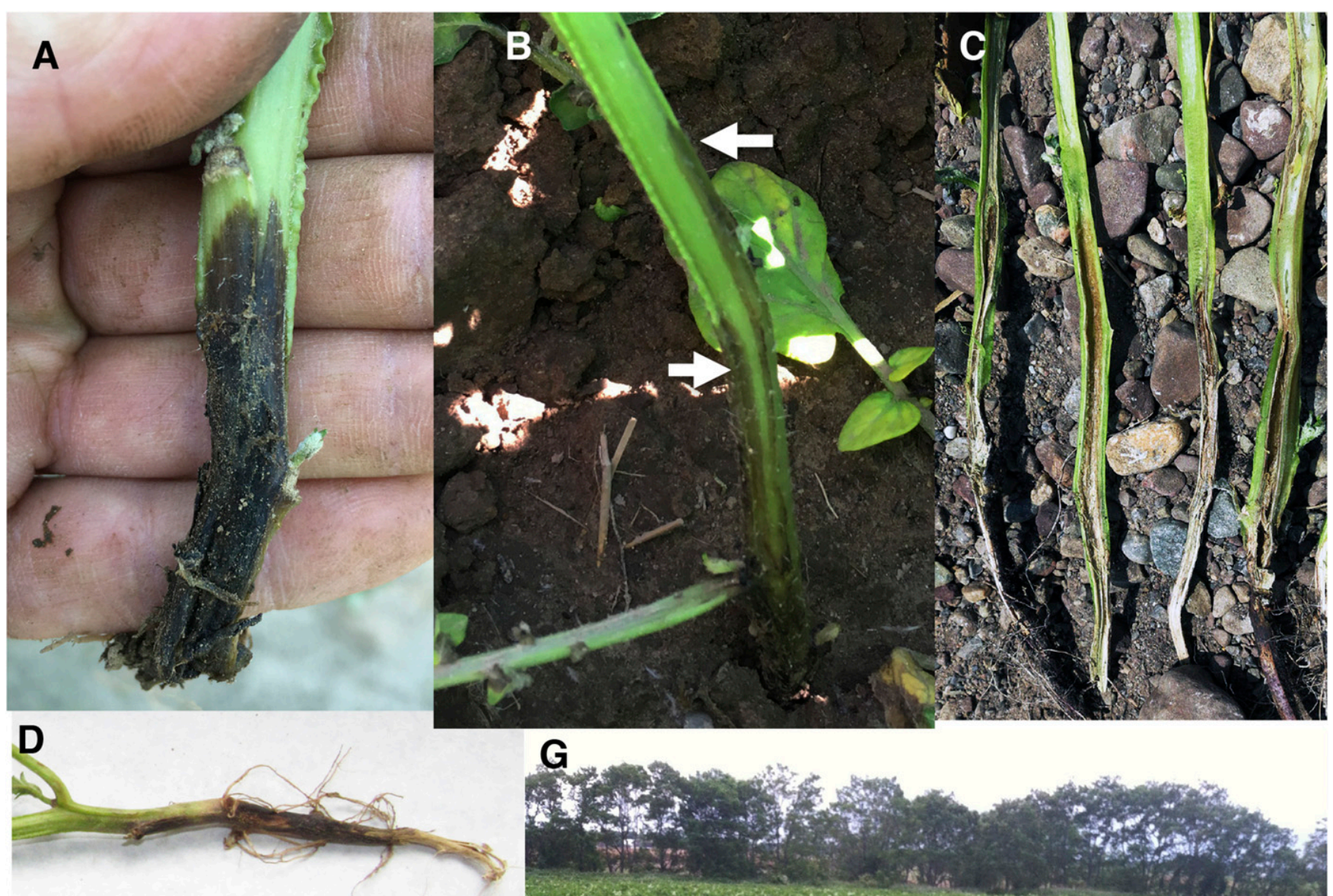

G
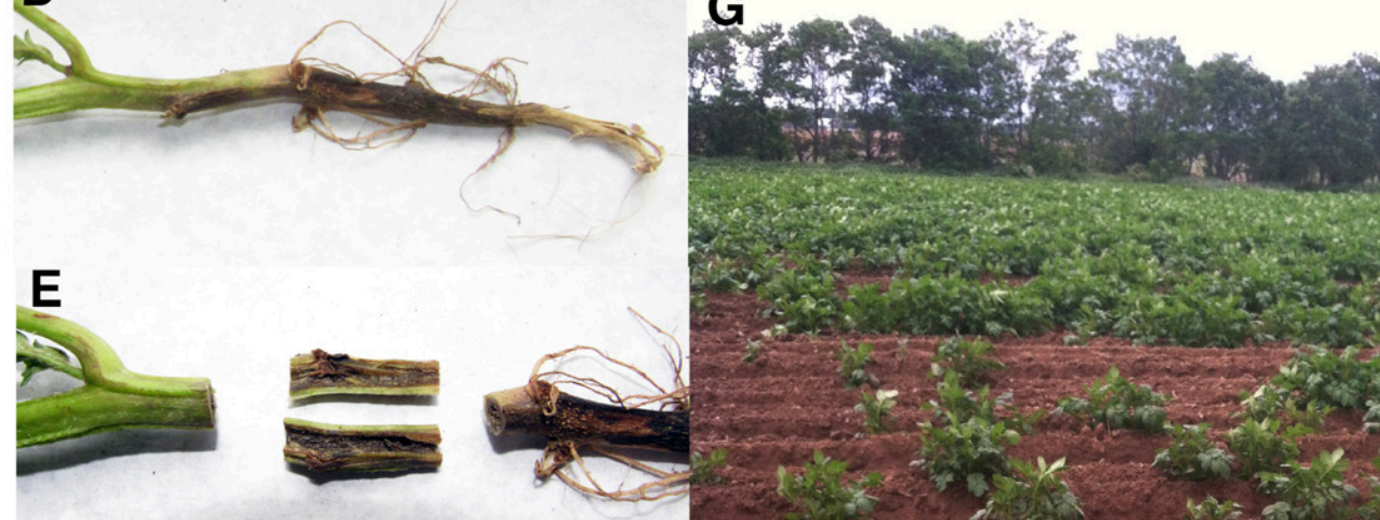

$\mathbf{F}$
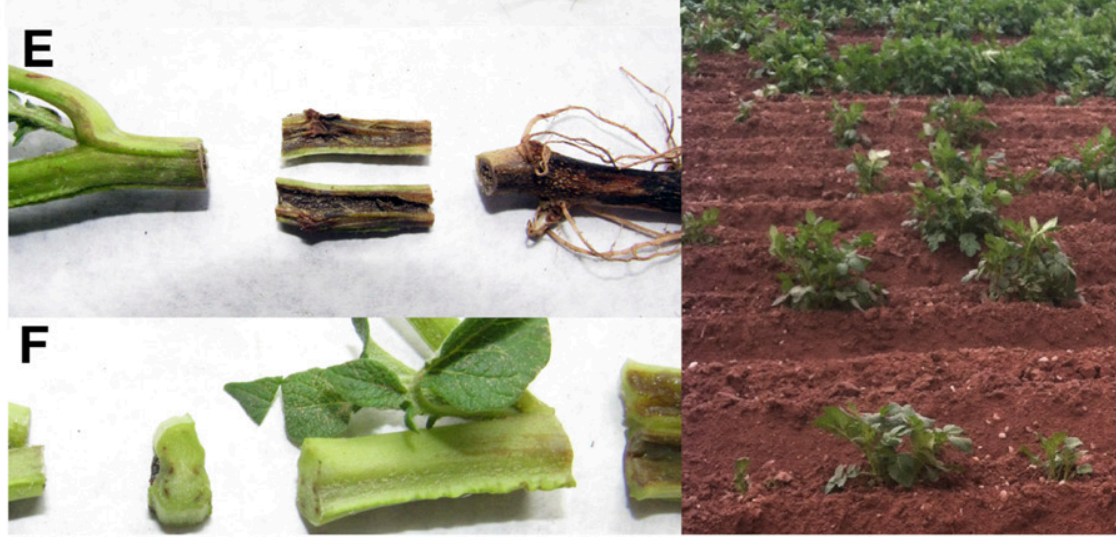

Fig. 2. Blackleg symptoms observed on field grown plants in the 2016 season. A, Inky rotting of basal portion of stem at soil line associated with complete collapse of the plant and/ or stem; the infection spread upward from the tuber. B, Basal stem showing brown streaking and discoloration of stem (arrows) where bacteria have move upward from the infected tuber. C, Basal portions of shoots showing a dry rotting of the stem cortex from the inside out. D, Basal region of an infected plant showing brown discoloration of the stem at the soil line. E, Same plant as in panel D cut open to reveal the dry internal rot. F, Basal region of an infected plant showing the pattern of brown discoloration of the stem from the soil line (right) upward into the aerial portion of the stem (left); a cross section of the stem (center left) shows a brown discoloration of vascular bundles. G, Spotty plant emergence (foreground) in a field planted with infected seed; the rear portion of the field was planted with a different seed lot of the same cultivar Marcy. 
with reference bacteria (positive controls), macerated tissue could be observed at the wound sites, while none was observed for the negative controls. For pathogenic isolates, the inoculated tissue was softened, loose, or oozing, though the extent varied among bacteria, as did the coloration from creamy to blackened. All isolates positive for soft rotting were also identified in the PCR assays as either Dickeya or Pectobacterium spp., with the exception of the pathogenic isolate NY1563A noted above (Table 1). Three bacterial isolates (NY1540B, NY1544A, NY1560A) were negative in the PCR assays, were nonpathogenic, and were employed as additional negative controls throughout the testing; sequence analyses suggested these isolates to be members of the family Enterobacteriaceae (data not shown), but these were not identified further.

All isolates testing positive in the tuber bioassay were also evaluated for their ability to cause disease in a stem inoculation assay. There was complete correspondence between the two bioassays; all isolates showing soft rotting activity in the tuber assay also caused a disease response in the stem assay on whole plants (Fig. 4). The disease responses varied in severity from a discoloration limited to the tissue immediately surrounding the wound site (clearly distinguishable from negative control inoculations) to an invasive movement of the bacterium up and down from the inoculation site and a collapse of the shoot. In a single experiment of this bioassay, each isolate was inoculated onto three stems and within-experiment variation in severity was observed for a given isolate from plant to plant, but there was always within-experiment consistency in the rating of isolates as pathogenic versus nonpathogenic (Fig. 4).

Species assignment based on $\mathrm{dnaX}$ gene sequencing and phylogenetic analyses. The $d n a X$ gene encodes a DNA polymerase III subunit, and its sequence with both conserved and variable regions is informative for distinguishing species of Dickeya and Pectobacterium (Sławiak et al. 2009; Zeigler 2003). We sequenced and aligned a 515-bp region of the 1,932-bp dnaX gene from each of the pathogenic isolates for use in developing phylogenetic trees showing the relationships between each of the isolates and of reference species/strains with publicly available sequenced genomes (NCBI, RefSeq Reference, and Representative Genome Database).

A condensed maximum likelihood tree was constructed with the partial $d n a X$ sequences from New York isolates and reference strains (Fig. 5). As expected, this dnaX analysis resolves the blackleg isolates and the Pectobacterium and Dickeya reference strains in two major branches of the phylogenetic tree referred to herein as the "Dickeya" and "Pectobacterium" clades. The Dickeya clade shows that 10 New York State Dickeya isolates cluster with D. dianthicola isolate ME23 (from Maine; accession number MF954601), IPO980 (from the Netherlands), and GBBC 2039 (from Belgium). The dnaX sequences for all New York Dickeya isolates were identical (represented by NY1528B, accession number MF954602), with 100\% nucleotide identity to $D$. dianthicola isolates ME23 and IPO980, and 99.8\% identity with GBBC 2039. Analysis of the Pectobacterium

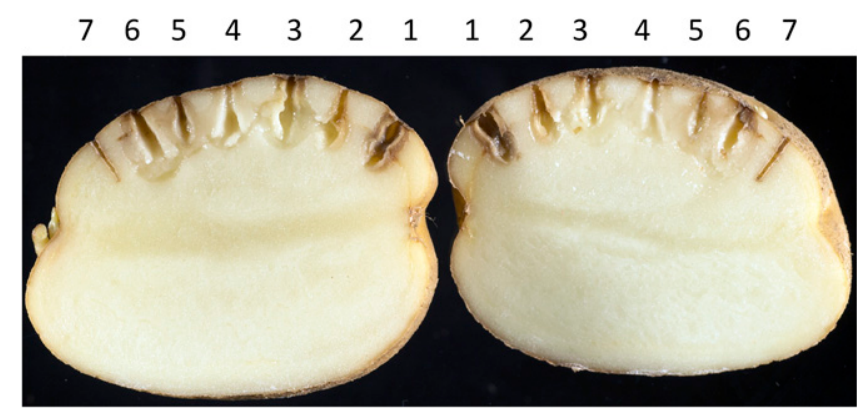

Fig. 3. Potato tuber bioassay for pathogenicity showing a range of responses in maceration and rotting. At $24 \mathrm{~h}$ postinoculation, the tuber was cut in half, and two halves of the same tuber are shown. The seven inoculation treatments are: 1) Pectobacterium carotovorum subsp. carotovorum WPP14, 2) $P$. atrosepticum 1043, 3) P. carotovorum subsp. brasiliense 1692, 4) P. parmentieri WPP163, 5) Dickeya dianthicola ME23, 6) D. dadantii 3937, and 7) negative control. clade indicated that the New York isolates likely to belong to three taxa. In the first taxon, two identical isolates, represented by NY1589H (accession number MF954606), cluster with $P$. atrosepticum ATCC33260 and SCRI 1043, showing 100 and 99.2\% identity, respectively. The second taxon consists of isolate NY1563A (accession number MF954607), a Pectobacterium sp. most closely related to $P$. carotovorum subsp. brasiliense strains SX309 and P. carotovorum subsp. carotovorum PCC21 (both with $99.4 \%$ identity). The third taxon corresponds with $P$. parmentieri WPP163, but can be further divided into three subgroups: i) a group with only one isolate, NY1532B (accession number MF954603), which shares $99.6 \%$ sequence identity with WPP163; ii) a group containing four isolates, represented by NY1533B (accession number MF954604) that shares $99.4 \%$ identity with WPP163, and iii) a group containing five $P$. parmentieri, represented by NY1548A (accession number MF954605) and sharing 99.2\% identity with WPP163. The dnaX sequences of NY isolates within each $P$. parmentieri subgroup were

A

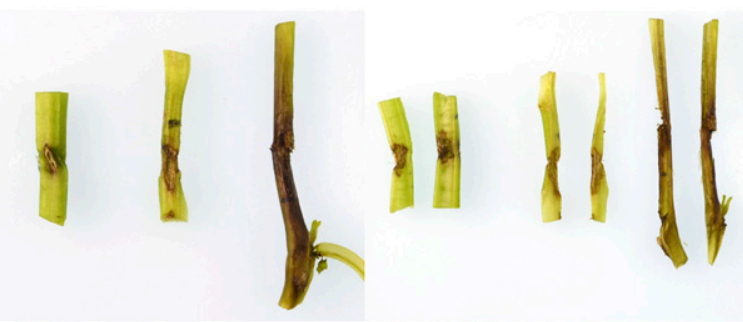

B
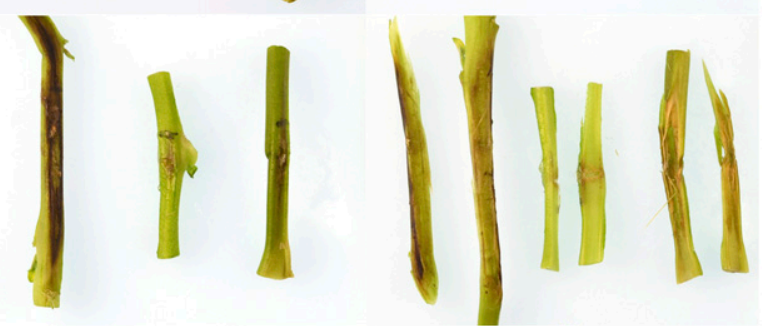

C
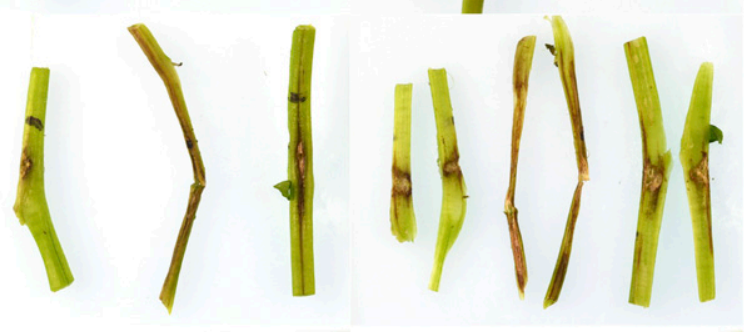

D
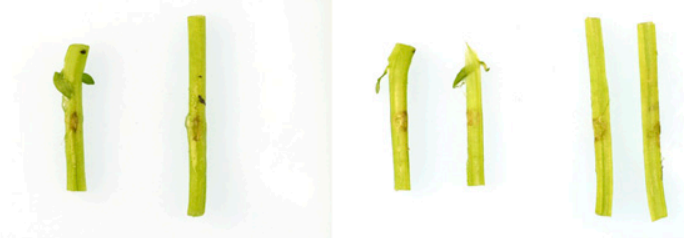

$\mathbf{E}$
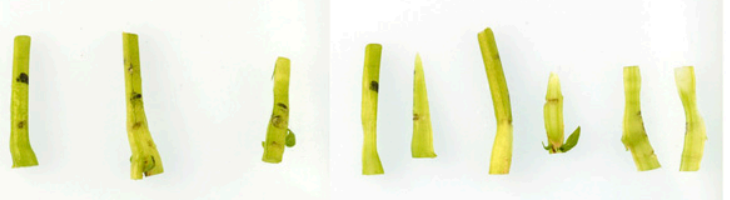

Fig. 4. Photographs of potato stem bioassay. Stems were inoculated and photographed 7 days post inoculation. The photos show a range in stem rot symptom severity, as seen with different pathogen isolates. Paired images are shown, with those of the left providing an external view of stems; photos on the right show the same stem sections cut longitudinally to reveal the extent of necrosis and spread. A, Pectobacterium parmentieri NY1548A; B, Dickeya dianthicola NY1558D; C, D. dianthicola ME23; D, nonpathogenic isolate NY1560A; $\mathbf{E}$, negative control: puncture wound only. 
identical. Thus, within this limited sampling, it is apparent that there are a mix of enterobacteria playing a role in the outbreak of blackleg in New York in 2016. The predominant isolates are $D$. dianthicola or $P$. parmentieri, while the previously recognized $P$. atrosepticum is still present.

\section{Discussion}

Blackleg disease has emerged in the past decade as a worsening problem affecting most potato production areas of the U.S. $P$. wasabiae (taxonomically revised as $P$. parmentieri) was reported associated with aerial stem rot of potato in Washington State in 2012 (Dung et al. 2012). In 2017, D. chrysanthemi, $P$. carotovorum subsp. brasiliensis, and $P$. parmentieri were all reported associated with potato blackleg in Minnesota and/or North Dakota (McNally et al. 2017a, b, 2018). Reports of blackleg in Maine associated with $D$. dianthicola and P. parmentieri (Ge et al. 2018; Hao et al. 2016; Jiang et al. 2016) were of particular concern to growers in the northeastern U.S., as Maine is the primary seed potato supplier for this part of the country. In response to blackleg disease problems in NY, this study was initiated in 2016 with the goal of isolating and identifying the pathogen(s) associated with affected plants.

Our experimental strategy to identify blackleg associated pathogen(s) was to isolate disease-associated bacteria and confirm their pathogenicity prior to DNA sequencing. Although the CVP medium is not highly selective for isolations and can be difficult to prepare, use, and interpret results on, it continues to be the method of choice in isolating soft rot bacteria. Combining isolation with a bioassay for pathogenicity provides a reliable scheme for obtaining and confirming soft rot bacteria in culture, and provides a means of identifying atypical or novel soft rot bacteria.

We based our taxonomic assignment on $\operatorname{dnaX}$ gene sequences and how isolates cluster with other related taxa in phylogenetic analyses. Identification based on a single gene sequence must be approached with caution, as results can be misleading due to horizontal gene transmission and other mechanisms of genetic exchange. While our taxonomic assignments are preliminary, several lines of reasoning suggest they accurately represent the identity of the pathogens in NY. Firstly, PCR assays run in parallel confirmed whether or not the isolates had DNA sequences representative of pathogenic Pectobacterium spp. or Dickeya spp. These primers have been in use and validated worldwide for many years, and their limitation appears to be false negatives, not misleading positive results (Dees et al. 2017; Potrykus et al. 2016). Secondly, dnaX sequences among the NY Dickeya isolates showed complete sequence identity and phylogenetic analysis showed discrete clustering for both the Pectobacterium and Dickeya isolates, with the exception of isolate NY1563A that clustered with two $P$. carotovorum subspecies. Thirdly, in previous phylogenetic analyses of soft rot associated bacteria, dnaX gene sequences have proven to yield accurate clustering and identification (Degefu et al. 2013; Potrykus et al. 2016; Sławiak et al. 2009). Lastly, we are cooperating in a comprehensive biochemical and multilocus sequence analysis (MLSA) with housekeeping genes to characterize of North American blackleg-associated bacteria. Data show that the phylogenetic relationships seen using $d n a X$ data alone are entirely consistent with the results using MLSA data; these analyses included the NY isolates described in this paper (Carol Ishimaru et al., unpublished).

During the latter phase of this study, 17 plant samples were tested by PCR at the same time that isolations were made. Fourteen of the samples were PCR positive for either Dickeya spp. or Pectobacterium spp. and these results were confirmed by the isolation of the corresponding pathogenic bacteria. Of the three PCR-negative samples, one proved to be positive in the isolation and pathogenicity testing. Thus, using PCR to test DNA extracted from infected plants was not prone to false positives, but the potential for false negatives needs to be considered. One isolate, NY1563A, was atypical in that the cultured bacterium was PCR negative, but it was clearly a soft rot pathogen in bioassays. DNA sequencing confirmed this isolate's relationship to $P$. carotovorum, but a more detailed analysis will be required to determine its identity. This type of result can occur given the dynamic aspect of taxonomic revision and discovery of new species of soft rot bacteria (Khayi et al. 2016; Sławiak et al. 2009; van der Wolf et al. 2014; Zhang et al. 2016).

The appearance of blackleg across most areas of U.S. potato production was unexpected given the previous success of seed potato certification programs in limiting the spread and impact of the associated pathogens. The emerging picture is that there are different causal bacteria in different regions, and thus there must be multiple origins of the pathogen. That said, D. dianthicola appears to be common to most regions and associated with an aggressiveness as described by Jiang et al. (2016). Based on dnaX sequence analysis, $D$. dianthicola isolated from plants in New York form a single clade, being genetically identical to each other and to D. dianthicola ME23 isolated in Maine in 2015. Although there is no clear explanation for the re-emergence of this disease in a more severe form over the past

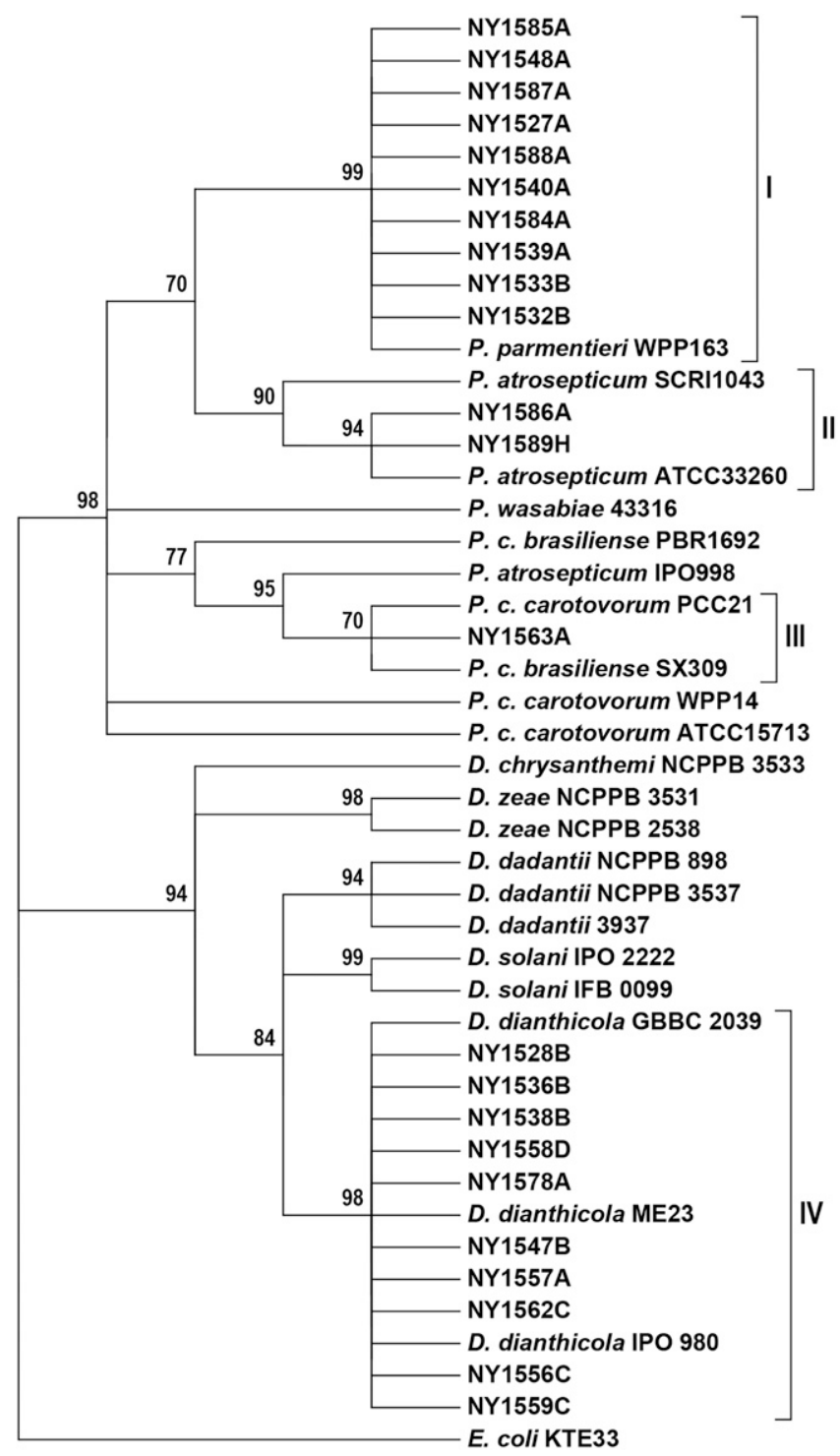

Fig. 5. Phylogenetic relationships of New York State potato blackleg pathogens and reference isolates of Pectobacterium and Dickeya. A phylogenetic tree was constructed based on partial sequences of the $d n a X$ gene from 11 Dickeya reference strains, 10 Pectobacterium reference strains, and 23 New York field isolates, with E. coli KTE33 included as an outgroup strain. Bifurcating branches with low bootstrap support (bootstrap values for 1,000 replicates below $70 \%$ ) were collapsed. New York isolates separated into four clusters. The first cluster containing 10 isolates is represented by $P$. parmentieri WPP163. The second cluster containing two isolates is represented by $P$. atrosepticum ATCC 33260 . One isolate fell into a third cluster, which includes multiple species, including $P$. carotovorum subsp. carotovorum PCC21, P. atrosepticum IP0998, P. carotovorum subsp. brasiliense strains SX309 and 1692, and P. wasabiae ATCC 43316. The fourth cluster containing 10 isolates is represented by $D$. dianthicola IPO980. 
decade, two factors likely have played a role. $D$. dianthicola (a former pathovar of the Erwinia chrysanthemi complex) is present worldwide and has a relatively wide host range (Bobev et al. 2014; Toth et al. 2011). The strain affecting potato may be newly selected, as it is described as being especially virulent on potato. $D$. dianthicola and other soft rotting bacteria have the ability to persist asymptomatically in potato tubers and plants (Pérombelon 2002). This characteristic of the pathogen's biology may contribute to the spread of the disease, as asymptomatic seed potato plants will escape detection during seed certification inspections even though they carry latent infections. Blackleg disease will appear in fields planted with latently infected tubers when the environment is conducive to disease development, such as with increased temperatures, anaerobic conditions, or other stress factors (Pérombelon 1974; Pérombelon and Kelman 1980). Regardless of the source of the pathogen, the management strategies for this disease will continue to rely on sanitation in the handling of seed potatoes and certification programs to limit the spread of infected seed. The latter will require a greater reliance on laboratory testing in order to reduce the level of latent infections in seed potatoes.

\section{Acknowledgments}

We thank Dr. Amy Charkowski for kindly providing type strains of Pectobacterium and Dickeya species and Carole Ishimaru for helpful discussion. We thank Zhongmeng Bao, Eric Markel, and Heather McLane for their help in facilitating experiments. We also thank cooperators Meg McGrath (Plant Pathology and Plant-Microbe Biology Section and Long Island Horticultural Research \& Extension Center, Cornell University), and Sandra Menasha and Carol MacNeil (Cornell Cooperative Extension) for their work in identifying affected fields, sampling, and interfacing with growers. We thank Sandra Menasha for her photo of a blackleg affected crop.

\section{Literature Cited}

Altschul, S. F., Gish, W., Miller, W., Myers, E. W., and Lipman, D. J. 1990. Basic local alignment search tool. J. Mol. Biol. 215:403-410.

Bobev, S. G., Van Vaerenbergh, J., and Maes, M. 2014. First report of Dickeya dianthicola causing blackleg on potato (Solanum tuberosum) in Bulgaria. Plant Dis. 98:275.

Cuppels, D., and Arthur, K. 1974. Evaluation of selective media for isolation of soft-rot bacteria from soil and plant tissue. Phytopathology 64:468

Czajkowski, R., Pérombelon, M. C. M., Jafra, S., Lojkowska, E., Potrykus, M., van der Wolf, J. M., and Sledz, W. 2015. Detection, identification and differentiation of Pectobacterium and Dickeya species causing potato blackleg and tuber soft rot: a review. Ann. Appl. Biol. 166:18-38.

Dees, M. W., Lebecka, R., Perminow, J. I. S., Czajkowski, R., Grupa, A., Motyka, A., Zoledowska, S., Śliwka, J., Lojkowska, E., and Brurberg, M. B. 2017. Characterization of Dickeya and Pectobacterium strains obtained from diseased potato plants in different climatic conditions of Norway and Poland. Europe. Eur. J. Plant Pathol. 148:839-851.

Degefu, Y., Potrykus, M., Golanowska, M., Virtanen, E., and Lojkowska, E. 2013. A new clade of Dickeya spp. plays a major role in potato blackleg outbreaks in North Finland. Ann. Appl. Biol. 162:231-241.

Dung, J. K. S., Johnson, D. A., and Schroeder, B. K. 2012. First report of Pectobacterium wasabiae causing aerial stem rot of potato in Washington State. Plant Dis. 96:1819.

Frechon, D., Exbrayat, P., Helias, V., Hyman, L. J., Jouan, B., Llop, P., Lopez, M. M., Payet, N., Pérombelon, M. C. M., Toth, I. K., van Beckhoven, J. R. C. M., van der Wolf, J. M., and Bertheau, Y. 1998. Evaluation of a PCR kit for the detection of Erwinia carotovora subsp. atroseptica on potato tubers. Potato Res. 41:163-173.

Gardan, L., Gouy, C., Christen, R., and Samson, R. 2003. Elevation of three subspecies of Pectobacterium carotovorum to species level: Pectobacterium atrosepticum sp. nov., Pectobacterium betavasculorum sp. nov. and Pectobacterium wasabiae sp. nov. Int. J. Syst. Evol. Microbiol. 53:381-391.

Ge, T., Jiang, H. H., Hao, J., and Johnson, S. B. 2018. First report of Pectobacterium parmentieri causing bacterial soft rot and blackleg on potato in Maine. Plant Dis. 102:437.

Glasner, J. D., Marquez-Villavicencio, M., Kim, H.-S., Jahn, C. E., Ma, B., Biehl, B. S., Rissman, A. I., Mole, B., Yi, X., Yang, C.-H., Dangl, J. L., Grant, S. R., Perna, N. T., and Charkowski, A. O. 2008. Niche-specificity and the variable fraction of the Pectobacterium pan-genome. Mol. Plant-Microbe Interact. 21:1549-1560.

Hao, J., Jiang, H., and Johnson, S. 2016. Detection and characterization of Dickeya species in the outbreak of blackleg disease of potato in Maine. Phytopathology 106:S2.2.
Hélias, V., Hamon, P., Huchet, E., Wolf, J. V. D., and Andrivon, D. 2012. Two new effective semiselective crystal violet pectate media for isolation of Pectobacterium and Dickeya. Plant Pathol. 61:339-345.

Humphris, S. N., Cahill, G., Elphinstone, J. G., Kelly, R., Parkinson, N. M., Pritchard, L., Toth, I. K., and Saddler, G. S. 2015. Detection of the bacterial potato pathogens Pectobacterium and Dickeya spp. using conventional and real-time PCR. Pages 1-16 in: Plant Pathology. Methods in Molecular Biology, vol. 1302. C. Lacomme, ed. Humana Press, New York.

Jiang, H. H., Hao, J. J., Johnson, S. B., Brueggeman, R. S., and Secor, G. 2016 First report of Dickeya dianthicola causing blackleg and bacterial soft rot on potato in Maine. Plant Dis. 100:2320.

Johnson, S. 2016. Dickeya, a new potato pathogen in Maine and elsewhere Phytopathology 106:S2.3.

Kang, H. W., Kwon, S. W., and Go, S. J. 2003. PCR-based specific and sensitive detection of Pectobacterium carotovorum ssp. carotovorum by primers generated from a URP-PCR fingerprinting-derived polymorphic band. Plant Pathol. 52: 127-133.

Khayi, S., Cigna, J., Chong, T. M., Quêtu-Laurent, A., Chan, K. G., Helias, V., and Faure, D. 2016. Transfer of the potato plant isolates of Pectobacterium wasabiae to Pectobacterium parmentieri sp. nov. Int. J. Syst. Evol. Microbiol. 66:5379-5383.

Laurila, J., Hannukkala, A., Nykyri, J., Pasanen, M., Hélias, V., Garlant, L., and Pirhonen, M. 2010. Symptoms and yield reduction caused by Dickeya spp. strains isolated from potato and river water in Finland. Eur. J. Plant Pathol. 126:249-262.

McGrath, M. T. 2017. Dickeya: A new disease causing major impact. Potato Country May/June:6-8.

McNally, R. R., Curland, R. D., Webster, B. T., Robinson, A. P., and Ishimaru, C. A. 2017a. First report of Pectobacterium carotovorum subsp. brasiliensis causing blackleg and stem rot in commercial and seed potato fields in Minnesota and North Dakota. Plant Dis. 101:1672.

McNally, R. R., Curland, R. D., Webster, B. T., Robinson, A. P., and Ishimaru, C. A. 2017b.First report of blackleg and tuber soft rot of potato caused by Pectobacterium parmentieri in Minnesota and North Dakota. Plant Dis. 101:2144.

McNally, R. R., Curland, R. D., Webster, B. T., Robinson, A. P., and Ishimaru, C. A. 2018. First report of stem rot on potato caused by Dickeya chrysanthemi in Minnesota. Plant Dis. 102:238.

Nassar, A., Darrasse, A., Lemattre, M., Kotoujansky, A., Dervin, C., Vedel, R., and Bertheau, Y. 1996. Characterization of Erwinia chrysanthemi by pectinolytic isozyme polymorphism and restriction fragment length polymorphism analysis of PCR-amplified fragments of pel genes. Appl. Environ. Microbiol. 62: 2228-2235.

Pérombelon, M. C. M. 1974. The role of the seed tuber in the contamination by Erwinia carotovora of potato crops in Scotland. Potato Res. 17:187-199.

Pérombelon, M. C. M. 2002. Potato diseases caused by soft rot erwinias: An overview of pathogenesis. Plant Pathol. 51:1-12. https://onlinelibrary.wiley. com/doi/abs/10.1046/j.0032-0862.2001.Shorttitle.doc.x

Pérombelon, M. C. M., and Kelman, A. 1980. Ecology of the soft rot erwinias. Annu. Rev. Phytopathol. 18:361-387.

Potrykus, M., Golanowska, M., Sledz, W., Zoledowska, S., Motyka, A., Kolodziejska, A., Butrymowicsz, J., and Lojkowska, E. 2016. Biodiversity of Dickeya spp. isolated from potato plants and water sources in temperate climate. Plant Dis. 100:408-417.

Potrykus, M., Sledz, W., Golanowska, M., Slawiak, M., Binek, A., Motyka, A., Zoledowska, S., Czajkowski, R., and Lojkowska, E. 2014. Simultaneous detection of major blackleg and soft rot bacterial pathogens in potato by multiplex polymerase chain reaction. Ann. Appl. Biol. 165:474-487.

Sambrook, J., Fritsch, E. F., and Maniatis, T. 1989. Molecular Cloning: A Laboratory Manual (2nd ed.). Cold Spring Harbor Laboratory, New York.

Sławiak, M., van Beckhoven, J. R. C. M., Speksnijder, A. G. C. L., Czajkowski, R., Grabe, G., and van der Wolf, J. M. 2009. Biochemical and genetical analysis reveal a new clade of biovar 3 Dickeya spp. strains isolated from potato in Europe. Eur. J. Plant Pathol. 125:245-261.

Toth, I. K., van der Wolf, J. M., Saddler, G., Lojkowska, E., Helias, V., Pirhonen, M., Tsror, L., and Elphinstone, J. G. 2011. Dickeya species: An emerging problem for potato production in Europe. Plant Pathol. 60:385-399.

van der Wolf, J. M., Nijhuis, E. H., Kowalewska, M. J., Saddler, G. S., Parkinson, N., Elphinstone, J. G., Pritchard, L., Toth, I. K., Lojkowska, E., Potrykus, M., Waleron, M., de Vos, P., Cleenwerck, I., Pirhonen, M., Garlant, L., Helias, V., Pothier, J. F., Pfluger, V., Duffy, B., Tsror, L., and Manulis, S. 2014. Dickeya solani sp. nov., a pectinolytic plant-pathogenic bacterium isolated from potato (Solanum tuberosum). Int. J. Syst. Evol. Microbiol. 64:768-774.

Zhang, Y., Fan, Q., and Loria, R. 2016. A re-evaluation of the taxonomy of phytopathogenic genera Dickeya and Pectobacterium using whole-genome sequencing data. Syst. Appl. Microbiol. 39:252-259.

Zeigler, D. R. 2003. Gene sequences useful for predicting relatedness of whole genomes in bacteria. Int. J. Syst. Evol. Microbiol. 53:1893-1190. 